\title{
Hydrogen-rich saline attenuates vascular smooth muscle cell proliferation and neointimal hyperplasia by inhibiting reactive oxygen species production and inactivating the Ras-ERK1/2-MEK1/2 and Akt pathways
}

\author{
YALI CHEN $^{1}$, JINYAO JIANG $^{2}$, HUIBING MIAO $^{3}$, XINGJUAN CHEN $^{4}$, XUEJUN SUN $^{5}$ and YONGJUN LI ${ }^{2}$ \\ ${ }^{1}$ Department of Cardiology, The Third Hospital of Hebei Medical University, Shijiazhuang, Hebei 050051; \\ ${ }^{2}$ Department of Cardiology, The Second Hospital of Hebei Medical University, Shijiazhuang, Hebei 050000; \\ Departments of ${ }^{3}$ Biochemistry and Molecular Biology, and ${ }^{4}$ Pharmacology, Institute of Basic Medicine, \\ Hebei Medical University, Shijiazhuang, Hebei 050011; ${ }^{5}$ Department of Diving Medicine, Faculty of \\ Naval Medicine, The Second Military Medical University, Shanghai 200433, P.R. China
}

Received October 31, 2012; Accepted December 24, 2012

DOI: $10.3892 /$ ijmm.2013.1256

\begin{abstract}
Hydrogen-rich saline has been reported to prevent neointimal hyperplasia induced by carotid balloon injury. The purpose of the present study was to further investigate the molecular mechanisms underlying this phenomenon. Daily injection of a hydrogen-rich saline solution (HRSS) in rats was employed to study the effect of hydrogen on balloon injury-induced neointimal hyperplasia and the neointima/ media ratio was assessed. HRSS significantly decreased the neointima area and neointima/media ratio in a dose-dependent manner. In vitro effects of hydrogen on fetal bovine serum (FBS)-induced vascular smooth muscle cell (VSMC) proliferation were also investigated. Hydrogen-rich medium (HRM) inhibited rat VSMC proliferation and migration induced by $10 \%$ FBS. FBS-induced reactive oxygen species (ROS) production and activation of intracellular Ras, MEK1/2, ERK1/2, proliferative cell nuclear antigen (PCNA), Akt were significantly inhibited by HRM. In addition, HRM blocked FBS-induced progression from the G0/G1 to the S-phase and increased the apoptosis rate of VSMCs. These results showed that hydrogen-rich saline was able to attenuate FBS-induced VSMC proliferation and neointimal hyperplasia by inhibiting ROS production and inactivating the Ras-ERK1/2-MEK1/2
\end{abstract}

Correspondence to: Dr Yongjun Li, Department of Cardiology, The Second Hospital of Hebei Medical University, Shijiazhuang 050000, P.R. China

E-mail: lyjbs2009@yeah.net

Dr Xuejun Sun, Department of Diving Medicine, Faculty of Naval Medicine, The Second Military Medical University, Shanghai 200433, P.R. China

E-mail: sunxjk@hotmail.com

Key words: hydrogen-rich saline solution, Ras-ERK1/2-MEK1/2, vascular smooth muscle cell and Akt pathways. Thus, HRSS may have potential therapeutic relevance for the prevention of human restenosis.

\section{Introduction}

Percutaneous transluminal coronary angioplasty (PTCA) is a procedure used to open stenotic coronary arteries due to cholesterol-laden atherosclerotic plaques (1). During PTCA, a cardiologist inserts a catheter carrying a deflated balloon in the femoral artery and up to the blocked site in the heart. The balloon is then inflated, allowing the blood to flow again (1). A long-term analysis showed that 10 - and 20 -year survival in PTCA patients was similar to survival in coronary artery bypass graft patients, but more interventions had to be repeated during the first year in PTCA patients (2). Indeed, restenosis, or blood vessel re-narrowing leading to restricted blood flow, still occurs in approximately $30 \%$ of patients within 6 months after undergoing PTCA. This complication represents a major disadvantage of PTCA therapies. Modern use of drug-eluting stents (DESs) has improved the outcome in these patients; however, $5-10 \%$ of patients are still affected by restenosis after DES placement (3).

Reactive oxygen species (ROS) and oxidative stress are involved in the pathogenesis of intimal thickening in atherosclerosis and restenosis $(4,5)$. Ohsawa et al (6) demonstrated that hydrogen is a potent anti-oxidant, able to selectively scavenge and neutralize hydroxyl radicals (such as ${ }^{\circ} \mathrm{OH}$ and $\mathrm{ONOO}^{-}$) and able to protect the brain against ischemiareperfusion (I/R) injury and stroke. Hydrogen treatment is able to reduce a number of markers of oxidative stress (7) and a number of clinical and experimental studies demonstrated that hydrogen acts as a scavenging agent, selectively neutralizing ROS in vivo and exerting potent cellular protective effects (8-11). Hydrogen has been shown to protect against restenosis in models of myocardial I/R injury $(12,13)$. Such results underline the use of hydrogen $\left(\mathrm{H}_{2}\right)$ gas in therapeutic medical applications. 
Although the use of $\mathrm{H}_{2}$ gas may pose certain safety issues, due to its inflammability, hydrogen-saturated saline (HRSS) has been shown to be safe, easy to administer and effective in carotid I/R injury (14), renal I/R injury $(15,16)$, acute liver injury (9), carbon monoxide intoxication (17) and atherosclerotic lesions (18). The exact mechanisms by which hydrogen exerts its effects on the vascular wall remain unknown. Aside from its anti-oxidant effects, there are certain indications that hydrogen may directly interact with some specific pathways $(14,19)$.

The present study examined the anti-proliferative effects of HRSS on abnormal vascular smooth muscle cells (VSMC) proliferation and investigated the mechanisms responsible for these effects.

\section{Materials and methods}

Preparation of hydrogen-rich saline and medium. HRSS and media (HRM) were produced as previously described (20). Briefly, hydrogen gas was dissolved in saline and in Dulbecco's modified Eagle's serum (DMEM; Gibco, USA) supplemented with $10 \%$ fetal bovine serum (FBS). We obtained saturation using a pressure of $0.4 \mathrm{MPa}$ for $6 \mathrm{~h}$. HRSS and HRM were maintained at $4^{\circ} \mathrm{C}$ and fresh solutions were prepared each week. Gas chromatography was used to confirm the hydrogen levels by the method described by Ohsawa et al (6). Cells were cultured in closed culture flasks.

Rat balloon injury model. All experimental procedures involving animals were approved by the Institutional Animal Care and Use Committee of the Hebei Medical University (Shijiazhuang, China). A total of 30 male Sprague-Dawley rats (weight, 280-320 g) were purchased from the animal center of the University and were divided into five groups: the sham group (no angioplasty) and the balloon-injured groups including the control group and 3 groups administered with HRSS at $2.5,5,10 \mathrm{ml} / \mathrm{kg}$, intraperitoneally, respectively.

Rats were anaesthetized with $3.6 \%(\mathrm{w} / \mathrm{v})$ chlorohydrate ( $1 \mathrm{ml} / 100 \mathrm{~g}$, intraperitoneally). Left common carotid artery (CCA) was balloon-denuded as previously described $(21,22)$. In brief, a median incision was performed on the anterior neck and left carotid arteries were isolated. A ligature in external carotid artery (ECA) was distally placed and the proximal ends of the CCA and internal carotid arteries (ICA) were clamped. An incision was performed in the ECA. Following blood removal, a $0.13 \mathrm{~mm}$ balloon catheter was delicately introduced into the CCA using the incision in the ECA. The balloon was inflated using saline to distend the CCA and pulled back to the ECA. The catheter was removed and the ECA's proximal end was ligated. Clamps were removed to re-establish blood flow.

Rats were then housed ( $12 \mathrm{~h}$ light cycles) and fed for 2 weeks (free access to food and water), and were then sacrificed using a pentobarbital overdose. Sections from carotid arteries from both sides were excised and fixed using $4 \%$ paraformaldehyde. Histologically stained sections were used to assess the extent of neointimal formation using computed planimetry. The intima-to-media (I/M) area ratio was calculated as the mean of these determinations (23).

Cell culture. VSMCs were isolated from the thoracic aorta of 10-12-week-old male Sprague-Dawley rats (23-25) and were cultured $\left(37^{\circ} \mathrm{C}\right.$ in a humidified $5 \% \mathrm{CO}_{2}$ incubator) in DMEM with $10 \%$ FBS, penicillin $100 \mathrm{U} / \mathrm{ml}$ and streptomycin $100 \mu \mathrm{g} / \mathrm{ml}$. Purity was confirmed by immunocytochemical localization of $\alpha$-smooth muscle actin. Upon confluence, cells were sub-cultured using $0.5 \%(\mathrm{w} / \mathrm{v})$ trypsin. Media were changed every 3 days and experiments were performed between 3 to 6 passages.

\section{Cell proliferation assay}

MTT assay. VSMCs $\left(4 \times 10^{3}\right.$ cells/well) were placed in a 96-well plate. Following incubation, sterile MTT $(20 \mu 1$ of $5 \mathrm{mg} / \mathrm{ml}$ ) was added, and incubated for $4 \mathrm{~h}$ at $37^{\circ} \mathrm{C} ; 150 \mu \mathrm{l}$ of dimethyl sulfoxide (DMSO) was then added. Absorbance $(490 \mathrm{~nm})$ was measured using a microplate reader (26).

BrdU assay. VSMCs were synchronized by serum deprivation and incubated with $10 \%$ FBS for $24 \mathrm{~h}$ with or without HRM. BrdU labeling mixture was then added and cultures were incubated for $12 \mathrm{~h}$ at $37^{\circ} \mathrm{C}$. Cell numbers were measured using a cell proliferation ELISA (Roche Molecular Biochemicals, Germany) (9,27).

Wound healing assay. The migration of VSMCs was evaluated by performing a cell-wounding assay according to a previously described method (28). Cells grown to $100 \%$ confluence on glass slides were scraped off the slides using a cell scraper. These cells were used to create a 3 -mm-wide wound and were then incubated at $37^{\circ} \mathrm{C}$ for $24 \mathrm{~h}$ in DMEM containing $10 \%$ FBS. Cells were then fixed with methanol and stained with hexamethyl pararosaniline. Cell migration activity was expressed as the number of cells that migrated into the wound area in each field.

Flow cytometric analysis of the cell cycle. VSMCs were synchronized at the G0-phase by serum depletion for $48 \mathrm{~h}$. After replenishment with fresh DMEM, the cells were preincubated with hydrogen-rich medium, and 10\% FBS was added to allow progression of cell cycle. After $48 \mathrm{~h}$, cells were trypsinized, centrifuged at $1,250 \mathrm{x}$ g for $5 \mathrm{~min}$. DNA was stained with propidium iodide (PI) $(50 \mu \mathrm{g} / \mathrm{ml})$ for $30 \mathrm{~min}$ at $37^{\circ} \mathrm{C}$, and $5 \times 10^{3}$ cells were then analyzed by flow cytometry.

Flow cytometric analysis of cell apoptosis. To assess apoptosis, we suspended HRM-cultured cells in buffer $(400 \mu 1 ; 10 \mathrm{mM}$ HEPES/NaOH; $140 \mathrm{mM} \mathrm{NaCl} ; 2.5 \mathrm{mM} \mathrm{CaCl}$; pH 7.4) after a careful wash.FITC-conjugated Annexin V (5 $\mu \mathrm{l}$; BD Biosciences, San Diego, CA, USA) was added and cells were incubated for $15 \mathrm{~min}$ at $4-8^{\circ} \mathrm{C}$ in the dark. PI $(10 \mu \mathrm{l})$ was added. After $5 \mathrm{~min}$, cells were washed again and $400 \mu \mathrm{l}$ of buffer was added. Cells were counted using a FACSCalibur (BD Biosciences).

RT-PCR for $\mathrm{Bax} / \mathrm{Bcl}-2$. Total RNA was extracted using the TRIzol reagent method and cDNA was obtained using a cDNA synthesis kit (TransScript first-strand) according to the manufacturer's instructions. Bcl-2 primers were: ATGGGGTGAAC TGGGGGAGGATTG (forward) and TTTCATATTTGTTT GGGGCAGGTC (reverse). Bax primers were: GAGAGGAT GGCTGGGGAGAC (forward) and GGTGAGCGAGGCGG TGAGGACT (reverse). DNA fragments were analyzed on a $1.5 \%$ agarose gel. Quantitative RNA data were expressed by normalizing band density to GAPDH (internal control). 
Western blot analysis. The cells and arterial tissue were solubilized or homogenized in lysate buffer on ice. Homogenates were centrifuged at $12,000 \mathrm{xg}$ for $30 \mathrm{~min}$ at $4^{\circ} \mathrm{C}$, yielding a cell protein supernatant. Proteins were subjected to SDS-PAGE and transferred to polyvinylidene difluoride membranes (PVDF; Millipore, Billerica, MA, USA). Samples were then probed with antibodies against: Ras, phosphorylated and nonphosphorylated ERK1/2, MEK1/2, proliferative cell nuclear antigen (PCNA), Akt and $\beta$-actin. Non-specific binding was blocked with $1.5 \%$ (w/v) evaporated skimmed milk (Difco, Franklin Lakes, NJ, USA) in TBS (154 mM NaCl, $10 \mathrm{mM}$ Tris base). Anti-rabbit or anti-mouse secondary antibodies conjugated to IRDYe700DX and IRDYe800 (1:5,000; Rockland Immunochemicals, Gilbertsville, PA, USA) were used to probe primary antibodies. Protein bands were detected and quantified on an Odyssey 2-color infrared imaging system (LI-COR Biosciences, Lincoln, NE, USA). The integrated signal densities were normalized first to $\beta$-actin (the loading control) and subsequently expressed in terms of the fraction abundance relative to control cells or arterial tissues. These experiments were performed in triplicate.

Immunohistochemistry and image analysis. Immunohistochemistry was performed as previously described (29). The control and sham groups were treated with anti-PCNA (1:100) antibody on Day 14 following balloon injury. Sections were counterstained with hematoxylin. Staining intensities were determined by measurement of the integrated optical density (IOD) with light microscopy using a computer-based Image-Pro Morphometric system. Measurements were conducted by 2 independent observers in a double-blind manner.

\section{Determination of reactive oxygen species}

DCFH-DA assay for intracellular reactive oxygen species. VSMCs $\left(1 \times 10^{5}\right.$ cells) were incubated with $10 \%$ FBS in the presence or absence of HRM for $12 \mathrm{~h}$. Cells were stained with $10 \mu \mathrm{M}$ of DCFH-DA for $30 \mathrm{~min}$ at $37^{\circ} \mathrm{C}$, detached with trypsin/EDTA, washed, re-suspended in PBS, and immediately analyzed by flow cytometry using a FACScan by fluorescence intensity (FL-1,525 nm) of 10,000 cells (23).

Determination of MDA concentration in VSMCs and hyperplasia neointima using TBARS production. Following incubation with HRM for $24 \mathrm{~h}$, cells were collected and washed with cold PBS, and hyperplastic neointimal tissues were homogenized. Tissue samples $(0.1 \mathrm{ml}), 8.1 \% \mathrm{SDS}$ $(0.2 \mathrm{ml}), 20 \%$ acetic acid buffer solution $(1.5 \mathrm{ml}, \mathrm{pH} 3.5)$, $1 \%$ total bile acid (TBA) thiobarbituric solution $(1.5 \mathrm{ml})$, and distilled water $(1 \mathrm{ml})$ were added. The solution was heated in a $95^{\circ} \mathrm{C}$ water bath for $40 \mathrm{~min}$ and then allowed to cool; it was then centrifuged at $3,500 \mathrm{rpm} / \mathrm{min}$ for $15 \mathrm{~min}$ and measured at $532 \mathrm{~nm}$ using a spectrophotometer $(14,30)$.

Determination of 8-OHdG in VSMCs and hyperplasia neointima. The 8-OHdG amounts were determined in VSMCs and hyperplastic neointimal tissues using a Bioxytech 8-OHdG-EIA kit. DNA was isolated using the DNAzol reagent and quantified. DNA (400 $\mu \mathrm{g})$ was resuspended in $50 \mu \mathrm{l} \mathrm{reac}-$ tion mixture containing $100 \mathrm{mmol} / \mathrm{l}$ sodium acetate $(\mathrm{pH}$ 5.0) and $5 \mathrm{mmol} / \mathrm{l} \mathrm{MgCl}_{2}$ and digested using DNaseI. Assay was performed according to the manufacturer's instructions (Shanghai Lanji Biological Institute, China).
Statistical analysis. Data are provided as the means \pm SEM. One-way analysis of variance (ANOVA) followed by the LSD-t-test were performed using SPSS 19.0 software. $\mathrm{P}<0.05$ was considered to indicate a statistically significant difference.

\section{Results}

ROS and Ras signaling pathways are involved in the effects of HRSS on neointimal hyperplasia. Balloon-induced intimal hyperplasia was evident in treated rats compared with rats of the control group (Fig. 1A). Results showed that 3 doses of HRSS were effective for prevention of neointimal formation in a dose-dependent manner (Fig. 1A). These findings showed neointimal area ratio reductions of $36.9,52.2$ and $71.8 \%$ $(\mathrm{P}<0.01)$ in HRSS-treated groups using $2.5,5 \mathrm{ml}$ and $10 \mathrm{ml} / \mathrm{kg}$ doses, respectively, compared with the balloon-injured control group (Fig. 1B).

Western blot analysis revealed that the activation of ERK1/2, MEK1/2 and Ras was strongly suppressed in a dosedependent manner in 14-day HRSS-treated samples compared with control samples $(\mathrm{P}<0.01)$ (Fig. 1E).

PCNA-positive cells were abundant in the balloon injury group. However, PCNA immunostaining was much less apparent in cells treated with HRSS. Staining intensities were lower in HRSS-treated rats $(\mathrm{P}<0.01)$ (Fig. $1 \mathrm{C}$ and $\mathrm{D})$.

Treatment with HRSS significantly inhibited the levels of carotid artery MDA and $8-\mathrm{OHdG}$ in a dose-dependent manner (Fig. 2).

HRM inhibits FBS-induced VSMC proliferation and migration. MTT assay showed that VSMC viability in the HRSS group was significantly lower than in the control group $(32.4 \pm 5.2$ vs. $73.3 \pm 5.1 \%$; $\mathrm{P}<0.01)$. Two VSMC cultures were treated with HRM for $48 \mathrm{~h}$; hydrogen was then ceased for one culture, while it was continued in the other. Following the removal of hydrogen, cells resumed viability (Fig. 3A). Cells without hydrogen treatment exhibited a BrdU index of $64.1 \pm 11.1 \%$, compared to $26.7 \pm 4.9 \%$ in the hydrogen group (Fig. 3B).

VSMC cell count was smaller in HRM-treated cells after 48 and $72 \mathrm{~h}$ (40 and 51\% reductions, respectively; $\mathrm{P}<0.01$ ) (Fig. 4A and B). VSMCs treated with FBS for $24 \mathrm{~h}$ showed greater mobility (FBS $58.3 \pm 13.9$ vs. hydrogen $18.6 \pm 5.8$ cells; $\mathrm{P}<0.01$ ) (Fig. 4C and D).

HRM prevents FBS-induced S-phase entry in VSMCs. Treatment with HRM inhibited FBS-induced G1-S progression, as demonstrated by the increase in G0/G1 cells $(68.8 \pm 2.2 \%)$ accompanied by concurrent decrease in S-phase cells $(16.7 \pm 2.0 \%)$ (Fig. 5A). These results suggest that hydrogen may prevent FBS-induced S-phase entry in VSMCs via a G0-G1 blocking mechanism.

HRM increases the proportion of apoptotic cells in VSMCs. Proportion of early apoptotic cells (Fig. 6A and B; lower right) increased from $1.36 \%$ (FBS-treated) to $2.1 \%$ (FBS + hydrogentreated) $(\mathrm{P}<0.05)$. These results also showed that the proportion of late apoptotic cells (Fig. 6A and B; upper right) increased from 6.96 to $13.47 \%(\mathrm{P}<0.01)$. 
A

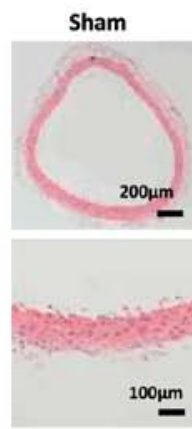

Control

$2.5 \mathrm{ml} / \mathrm{kg} \mathrm{H}$

$5.0 \mathrm{ml} / \mathrm{kg} \mathrm{H}$

$10.0 \mathrm{ml} / \mathrm{kg} \mathrm{H}$

B
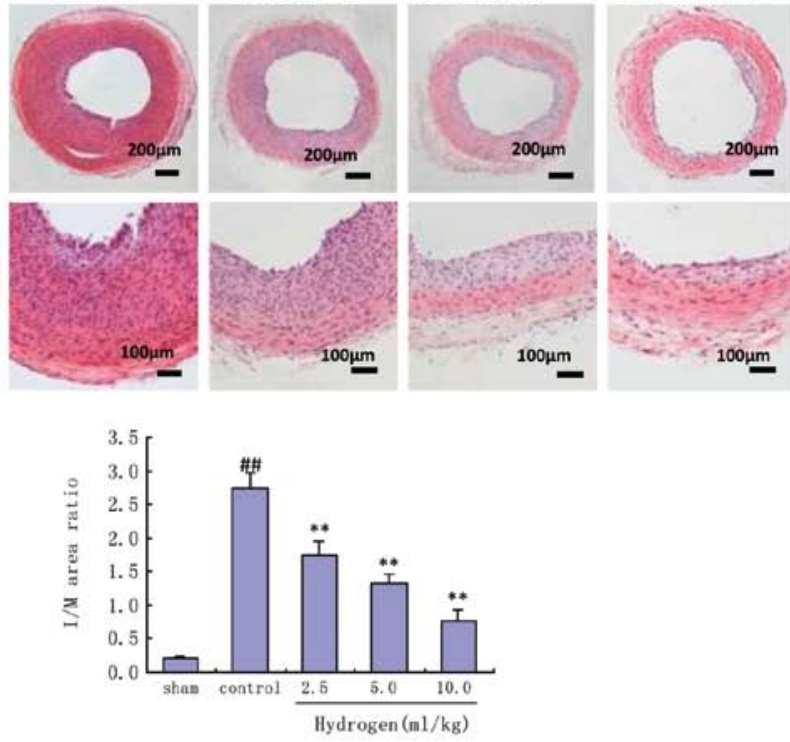

C

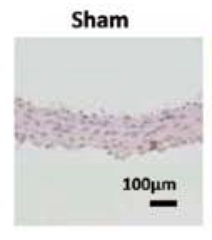

Control $\quad 2.5 \mathrm{ml} / \mathrm{kg} \mathrm{H}_{2}$

$5.0 \mathrm{ml} / \mathrm{kg} \mathrm{H}$

$10.0 \mathrm{ml} / \mathrm{kg} \mathrm{H}_{2}$

D

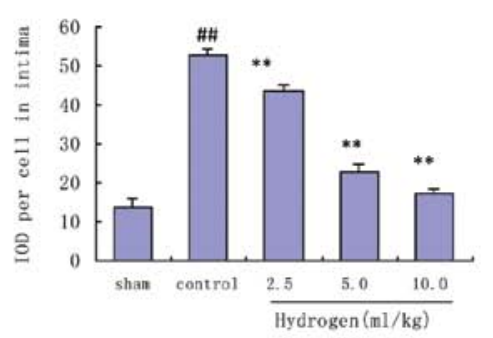

E
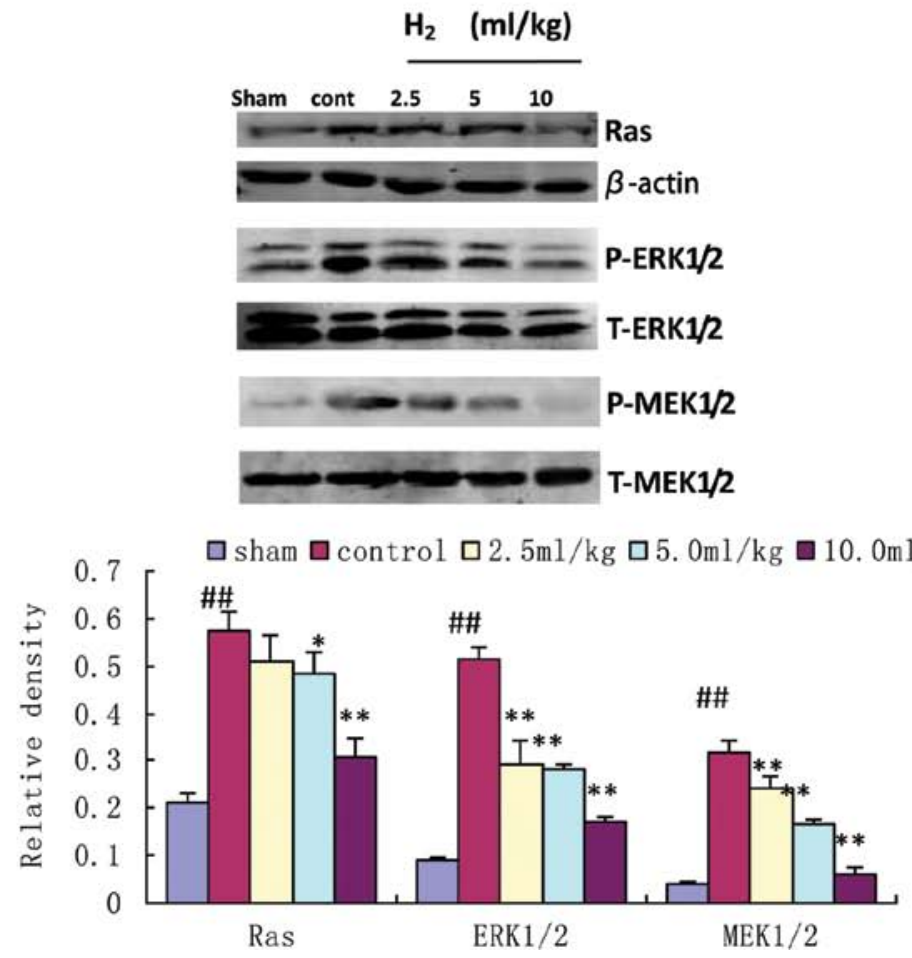

Figure 1. Hydrogen-rich saline inhibits injury-induced neointimal hyperplasia in rat carotid arteries. (A) Histological sections and (B) the intima to media area ratio of carotid arteries 14 days after balloon injury. ${ }^{\# \#} \mathrm{P}<0.01, \mathrm{n}=6$, vs. sham group; ${ }^{* *} \mathrm{P}<0.01, \mathrm{n}=6$, vs. control group. (C) Immunostaining and (D) integrated optical density (IOD) per cell of intima in carotid artery section treated as in panel (A). ${ }^{\# \#} \mathrm{P}<0.01, \mathrm{n}=6$, vs. sham group; ${ }^{* *} \mathrm{P}<0.01$, $\mathrm{n}=6$, vs. control group. (E) Western blot analysis of the active forms of Ras, ERK1/2 and MEK1/2 in carotid arteries 14 days after balloon injury. ${ }^{\# \#} \mathrm{P}<0.01, \mathrm{n}=4$, vs. sham group; ${ }^{*} \mathrm{P}<0.05 ;{ }^{* *} \mathrm{P}<0.01$, $\mathrm{n}=4$, vs. control group. 

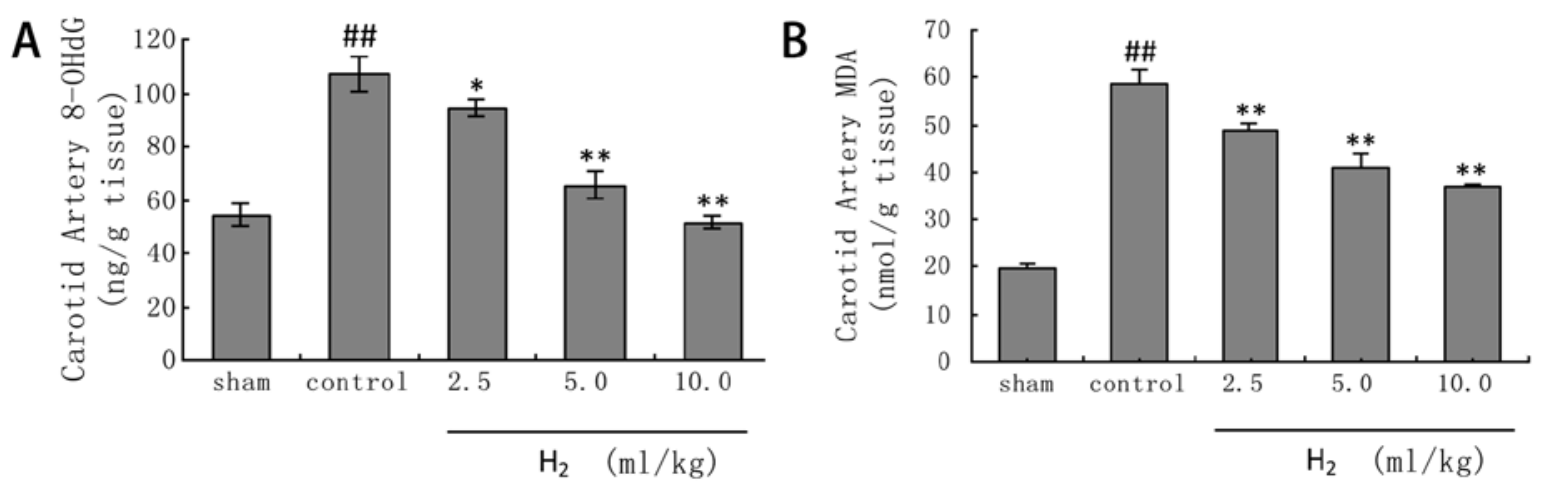

Figure 2. Hydrogen-rich saline inhibits injury-induced ROS production in rat carotid arteries. (A) 8-OHdG levels of injured carotid arteries. ${ }^{*} \mathrm{P}<0.05$; ${ }^{* *} \mathrm{P}<0.01$, $\mathrm{n}=3$, vs. control group; ${ }^{\# \#} \mathrm{P}<0.01, \mathrm{n}=3$, vs. sham group. (B) MDA levels of injured carotid artery. ${ }^{* *} \mathrm{P}<0.01, \mathrm{n}=4$, vs. control group; ${ }^{\# \#} \mathrm{P}<0.01, \mathrm{n}=4$, vs. sham group.
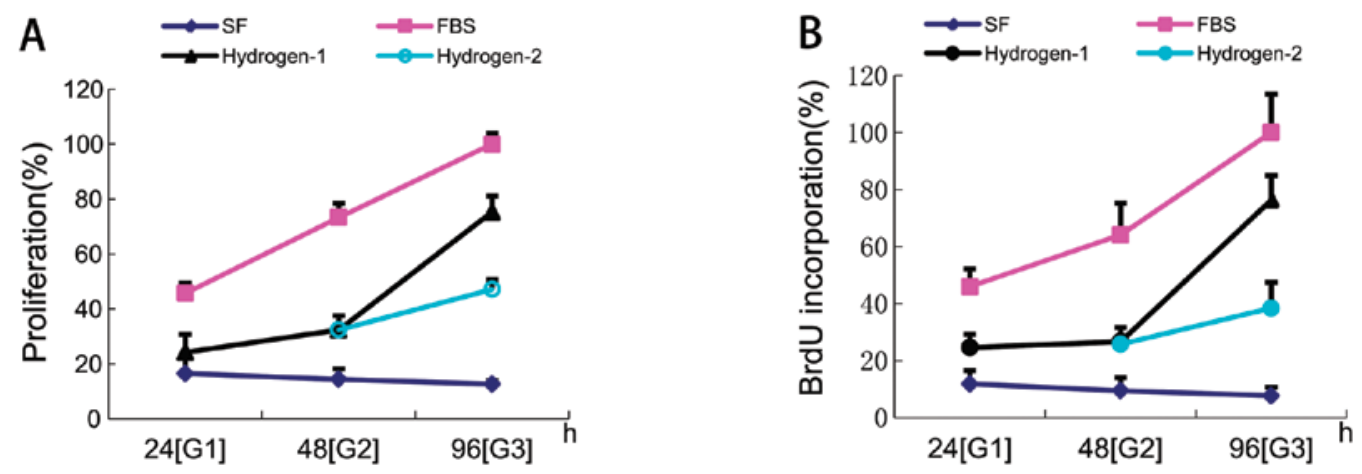

Figure 3. Effects of hydrogen on 10\% FBS-induced rat VSMC proliferation and DNA synthesis. Cells were cultured in the absence or presence of hydrogen for $24 \mathrm{~h}$ (G1) and $48 \mathrm{~h}$ (G2). Hydrogen was continued for another $48 \mathrm{~h}$ (G3, line-Hydrogen-2) or ceased (G3, line-Hydrogen-1). Viability was assessed using (A) MTT and (B) BrdU. Data are expressed as the means \pm SEM. ${ }^{*} \mathrm{P}<0.01$, vs. the FBS group; ${ }^{~} \mathrm{P}<0.01$, vs. the serum-free (SF) group; and $\mathrm{P}<0.01$, independent$\mathrm{t}$-test, for the recovery experiment.
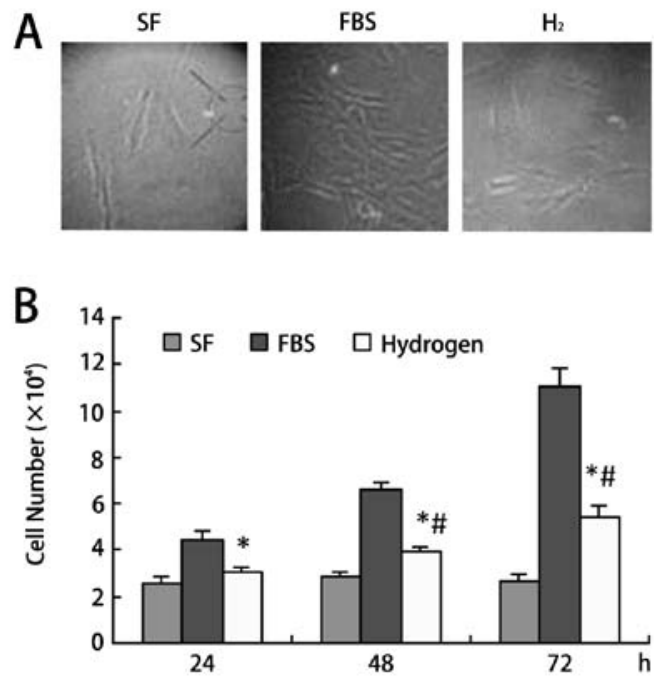

$\mathrm{C}$
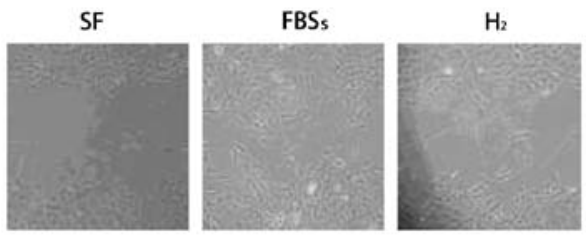

D

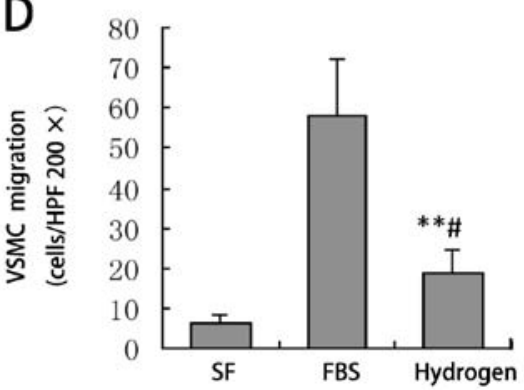

Figure 4. Effects of hydrogen on wound healing. (A) Inhibitory effects of hydrogen on cell number. Representative images of different groups are shown at 72 h. (B) Number of cells at different time points. " $P<0.01$, compared with the FBS group. " $P<0.01$, compared with the serum-free (SF) group. (C) Effects of hydrogen on wound healing. Representative images $24 \mathrm{~h}$ post-wounding. (D) VSMC migration from 10 independent wounds. ${ }^{* *} \mathrm{P}<0.01$, vs. FBS group; ${ }^{*} \mathrm{P}<0.05$, vs. SF group.

Following HRM treatment, a significant increase in Bax/ Bcl-2 ratio $(\mathrm{P}<0.01)$ indicated that $\mathrm{VSMCs}$ were, in fact, progressing towards apoptosis (Fig. 6C and D).
ROS is involved in the effect of HRM on FBS-stimulated VSMCs. FBS treatment significantly induced intracellular peroxide production (Fig. 7A and B). ROS generation in cells 


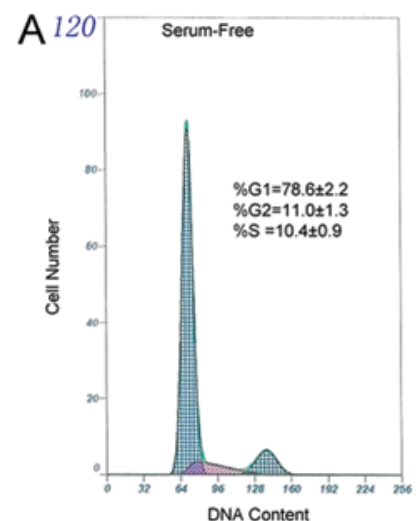

B

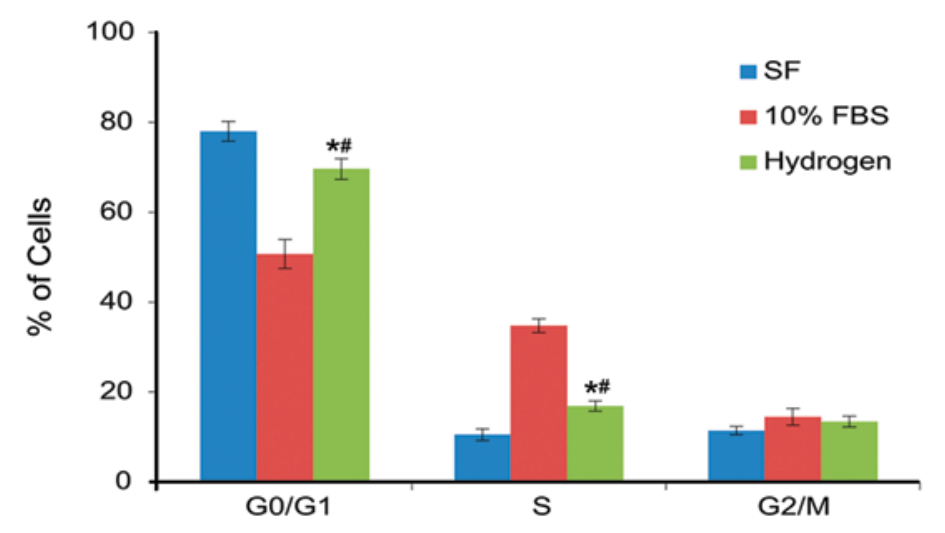

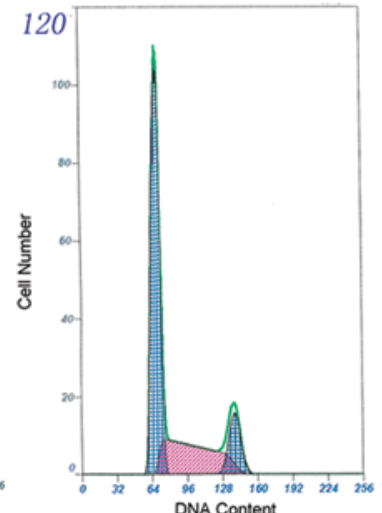

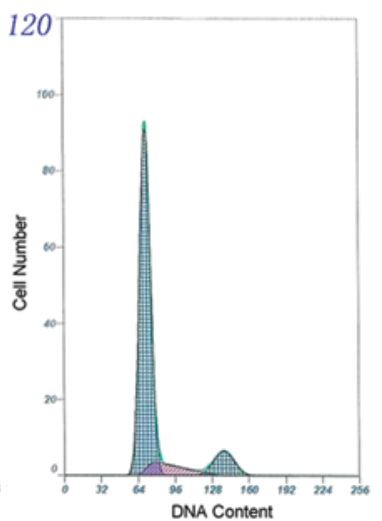

Hydrogen

Figure 5. Effect of hydrogen on cell cycle progression. (A) Hydrogen inhibited VSMCs from entering the S-phase of the cell cycle. (B) Comparison of cell cycle phase in VSMCs. "P<0.01, vs. the serum-free (SF) group; ${ }^{P} \mathrm{P}<0.01$, vs. $10 \%$ FBS group. Results are from 3 independent experiments and represent means \pm SEM.

A

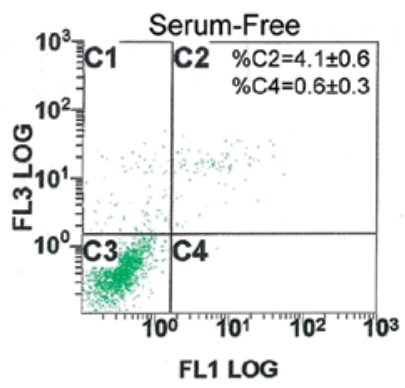

B

D

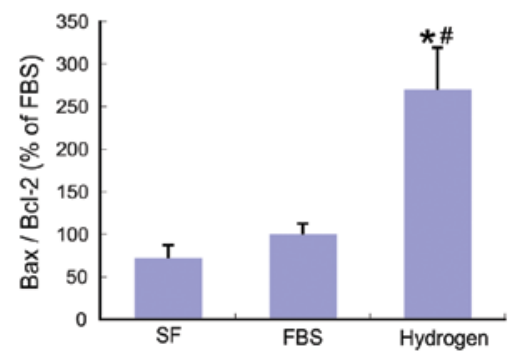

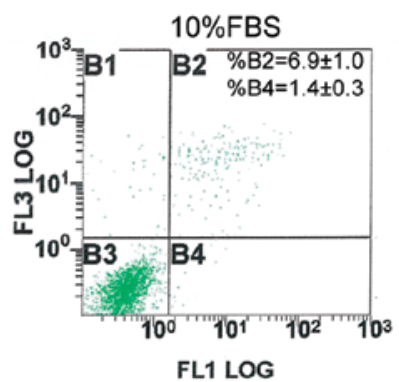

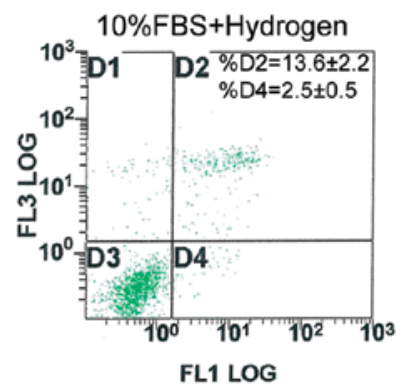

C
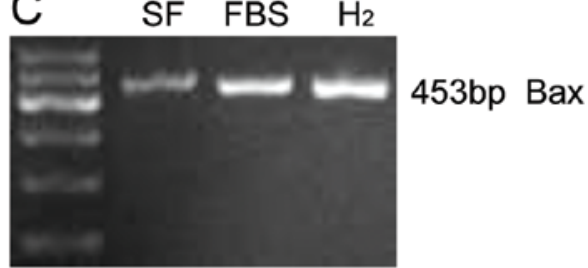

$453 b p$ Bax

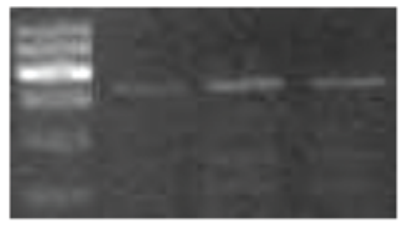

334bp Bcl-2

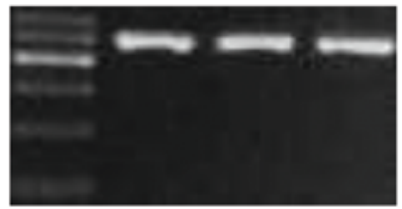

496bp GAPDH

Figure 6. Flow cytometry analyses of cell apoptosis. (A) Hydrogen induced early and late apoptosis. (B) Comparison of early and late apoptosis in VSMCs. ${ }^{* *} \mathrm{P}<0.01$, vs. the serum-free (SF) group; ${ }^{\#} \mathrm{P}<0.05 ;{ }^{\# \#} \mathrm{P}<0.01$, vs. $10 \%$ FBS group. (C) Levels of Bcl-2 and Bax. (D) Hydrogen increased ratio of Bax/Bcl-2. ${ }^{*} \mathrm{P}<0.01$, vs. SF; ${ }^{*} \mathrm{P}<0.01$, vs. FBS. Results are from 3 independent experiments and represent means $\pm \mathrm{SEM}$. 

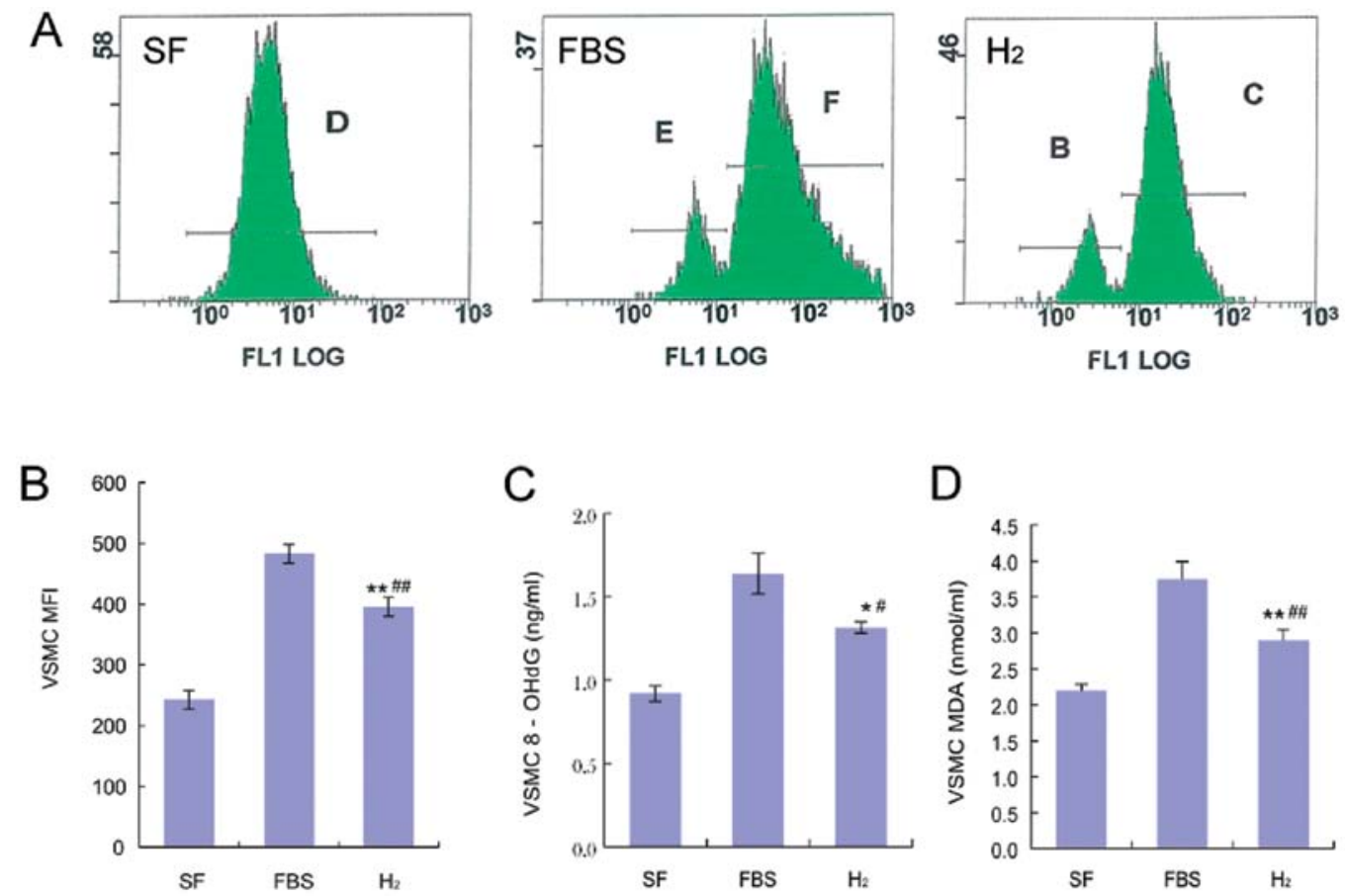

Figure 7. Hydrogen-rich medium inhibits FBS-induced ROS production. (A) Levels of intracellular peroxide in the presence of hydrogen-rich medium for $48 \mathrm{~h}$. (B) Mean fluorescence intensity (MFI) of DCF was expressed as means \pm SEM. ${ }^{* *} \mathrm{P}<0.01, \mathrm{n}=3$, vs. the FBS group; ${ }^{\# *} \mathrm{P}<0.01, \mathrm{n}=3$, vs. the serum-free (SF) group. (C) Effect of hydrogen on 8 -OHdG. ${ }^{*} \mathrm{P}<0.05$, n=3, vs. FBS group; ${ }^{*} \mathrm{P}<0.05, \mathrm{n}=3$, vs. SF. (D) Effect of hydrogen on MDA concentration. ${ }^{*} \mathrm{P}<0.05$, $\mathrm{n}=3$, vs. FBS group; ${ }^{*} \mathrm{P}<0.05, \mathrm{n}=3$, vs. $\mathrm{SF}$ group.
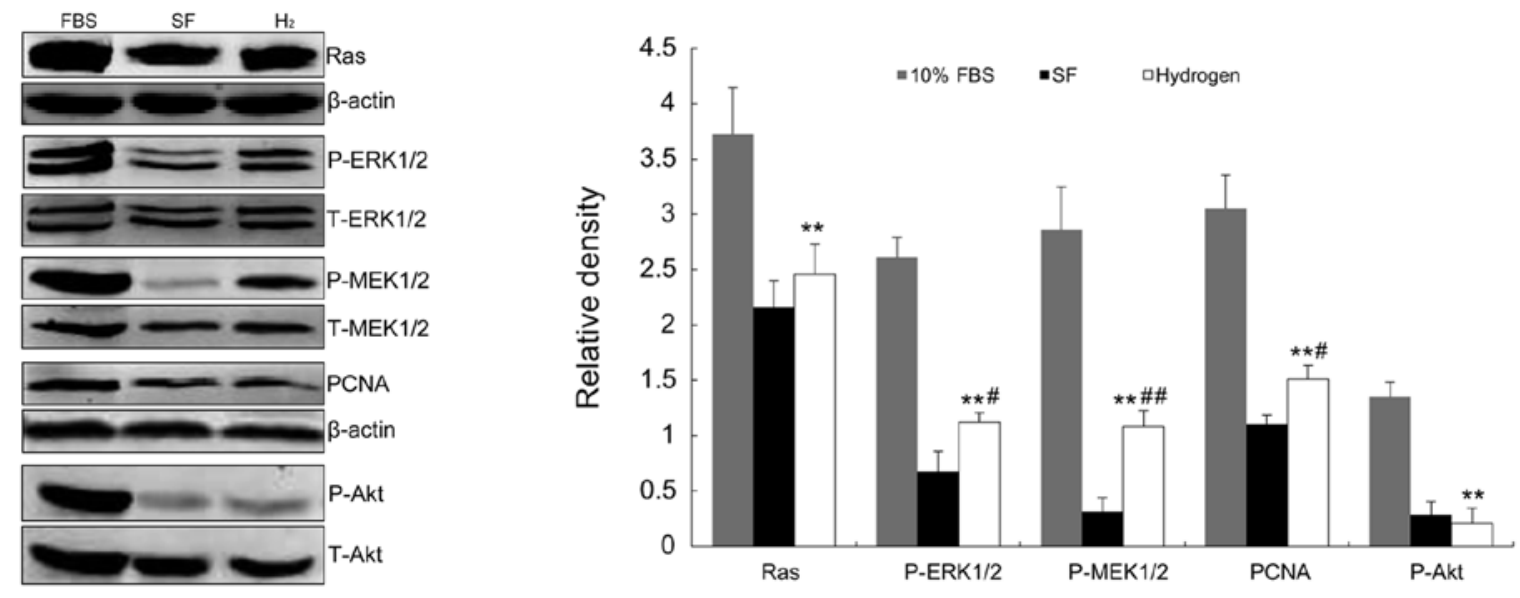

Figure 8. Inhibitory effects of hydrogen on Ras, ERK1/2, MEK1/2, PCNA and Akt activation. Means \pm SEM from 3 to 5 independent experiments. SF, serumfree medium. ${ }^{* *} \mathrm{P}<0.01$ vs. FBS group; ${ }^{\#} \mathrm{P}<0.05 ;{ }^{\# \#} \mathrm{P}<0.01$, vs. SF group.

treated with HRM was 395.6 \pm 16.1 , compared with $483.0 \pm 15.1$ for controls $(\mathrm{P}<0.01)$.

The 8-OHdG levels in cells treated with HRM were $1.3 \pm 0.0 \mathrm{ng} / \mathrm{ml}$, compared to $1.6 \pm 0.1 \mathrm{ng} / \mathrm{ml}$ in controls $(\mathrm{P}<0.01)$ (Fig. 7C). Fig. 7D shows that treatment with HRM significantly inhibited MDA generation (FBS $3.7 \pm 0.2$ vs. hydrogen 2.9 \pm 0.1 ; $\mathrm{P}<0.01)$.

Ras-MEK1/2-ERK1/2 pathway and Akt phosphorylation are involved in the effect of HRM on FBS-stimulated VSMCs. Stimulation of cells with $10 \%$ FBS induced Ras activation. Cells treated with HRM exhibited a slight inhibition of FBS-induced
Ras activation (Fig. 8A). Treatment of FBS-stimulated VSMCs with HRM markedly decreased phosphorylated MEK1/2 levels (Fig. 8C). Data showed that FBS also induced a profound increase in ERK1/2 activation. Treatment with HRM significantly inhibited FBS-stimulated phosphorylation of ERK1/2 (Fig. 8B). By contrast, total ERK1/2 protein levels were not altered by treatment with hydrogen. FBS induced a profound increase in Akt activation. The level of Akt phosphorylation following FBS stimulation was also significantly inhibited by treatment with HRM (Fig. 5E). As shown in Fig. 8D, FBS-induced PCNA expression was significantly inhibited by HRM by $50 \%(\mathrm{P}<0.01)$. 


\section{Discussion}

In the process of opening the artery, PTCA may injure the vascular wall (31). VSMC proliferation in the arterial wall is crucial in the development of post-angioplasty restenosis and atherosclerosis $(32,33)$. Currently, the most common approach to reduce neointimal formation and its consequences is the use of DES (34). However, DES presents a number of issues, such as incomplete stent coverage, inadequate stent placement or failure of the eluting drug to inhibit VSMC proliferation (35-37). The current study demonstrates that hydrogen inhibits VSMC proliferation and migration and provides important mechanistic information; this inhibitory effect involves the blockage of the G1-S-phase cell cycle progression, thus increasing apoptosis and inhibition of Ras-MEK1/2-ERK1/2 and Akt signaling pathways. HRSS treatment also inhibits neointimal hyperplasia induced by balloon injury via suppression of the Ras-MEK1/2-ERK1/2 signaling pathway.

Oxidative stress is involved in vascular diseases $(38,39)$. Initial observations focused on ROS derived from invading macrophages, indicating possible involvement in oxidative lipid modifications of vessel walls. ROS can attack circulating lipoproteins, contributing to atherosclerotic plaque development (40), and can attack vessel walls, maintaining a pro-inflammatory state (41). Ohsawa et al (18) used an apolipoprotein $\mathrm{E}$ knockout mouse model to demonstrate the role of hydrogen as an antioxidant. In their study, oral ingestion of HRSS for 6 months prevented atherosclerosis development by decreasing oxidative stress in the blood vessels. Moreover, controlled ROS production occurs in all vascular cells, where these compounds act as secondary messengers in the regulation of varied cellular functions. Notably, VSMC proliferation and stenosis following vascular injury was shown to coincide with elevated ROS levels in experimental animals $(42,43)$.

The $\mathrm{O}_{2}$ and $\mathrm{H}_{2} \mathrm{O}_{2}$ ROS are primarily detoxified by antioxidant defense enzymes, unlike radical ${ }^{\circ} \mathrm{OH}$ and $\mathrm{ONOO}^{-}$species. Hydrogen gas has been demonstrated to selectively reduce these 2 ROS species (6). Thus, 8 -OHdG formed by deoxyguanosine in DNA in the presence of hydroxyl free radicals may be a useful biomarker for intracellular oxidative stress (44). MDA is also a non-specific marker of lipid peroxidation. Assessment of 8-OHdG levels demonstrated that increasing ROS levels were inhibited by HRSS in vitro in FBS-treated VSMCs. Furthermore, increases in ROS levels in neointimal tissues in vivo were inhibited by HRSS. These findings are consistent with previous reports, including the report by Qin et al (14) that demonstrates hydrogen ability to reduce injury-induced excess superoxide anions and inflammation. Results from the present study also show that ROS reduction coincides with a decrease in VSMC proliferation and proliferative pathways. This moderate antioxidant ability indicates that hydrogen may cause only minimal disturbance to normal physiological functions involving ROS.

Upon exposure to growth factors or serum, proteintyrosine kinase (PTK) receptors are activated, resulting in the activation of Ras/Raf/MAPK/MEK and downstream proteins. ERK also plays a central role in this pathway (45). It has also been suggested that ERK may play a pivotal role in VSMC proliferation control $(46,47)$. Specifically, it may inhibit MAPK phosphorylation, thus markedly inhibiting VSMC growth in vitro (48). The activation of ERK1/2 can increase the expression of downstream transcription genes, such as cyclin D1, resulting in protein synthesis and cell proliferation (49). Therefore, confirmation that HRSS inhibits the ERK pathway partly explains the antiproliferative mechanisms of such treatments.

Furthermore, Ras, a major upstream signaling protein of Raf-MEK1/2-ERK1/2, is primarily stimulated by mitogenic factors (50). It plays a pivotal role in G1 progression and in the G1-S transition. Hydrogen treatment significantly and efficiently reduces phosphorylated ERK (active form) and phosphorylated MEK, resulting in a slight decrease in Ras expression, suggesting that HRSS is capable of effectively inhibiting the ERK pathway. This effect likely contributes to the observed anti-proliferative activity of hydrogen in VSMCs. HRSS effects on the ERK signaling cascade activated by balloon injury may also be associated with Ras-MEK1/2-ERK1/2 signaling pathway involvement in suppression of neointimal hyperplasia. Dose-dependent inhibition of ROS, VSMC proliferation and of ERK1/2, MEK1/2, and Ras activations were observed in cases of balloon injury treated with lercanidipine (51). Our results indicate that the same outcomes are achieved simply using hydrogen and that hydrogen acts through similar mechanisms. These results further support the ability of HRSS to inhibit the FBS- or injury-induced ERK1/2 signaling cascade, thus affecting VSMC proliferation both in vitro and in vivo, which has not previously been reported as a major hydrogen effect in a review on hydrogen's medical properties (7). HRSS was also demonstrated to inhibit the PI3K pathway in VSMCs. PI3K activates Akt (serine/threonine kinase). In its active state, Akt promotes cell survival and growth (52); however, it remains unclear whether the PI3K pathway is affected by HRM treatment. If HRM can inhibit the PI3K pathway in VSMCs, this effect would also contribute to the anti-proliferative effect of HRM on VSMCs.

Suppressed PCNA levels in the G0/G1-phase were associated with hydrogen treatment, demonstrating the effect of hydrogen treatment on the regulation of VSMCs at the nuclear level. PCNA is synthesized in the early G1- and S-phase, making it a useful marker for proliferation $(50,53)$. The antiproliferative effect of HRM may result from its ability to block the entry of cells into the S-phase due to interference in the early G0/G1 transition phase. Preventing cell cycle transition between the G1- and S-phase in VSMCs may be beneficial in reducing cell proliferation and migration, as well as restenosis $(54,55)$. The current evaluation of VSMC cell cycle alteration in response to treatment with HRM showed a considerable increase in cells in the G0/G1-phase and a concomitant decrease in S-phase cells, which may result from reduced proliferation, increased apoptosis, or a combination of the two. Additionally, HRM treatment revealed increased apoptosis rates. Cellular apoptotic events are known to be governed by levels of anti-apoptotic (Bcl-xL family) and pro-apoptotic proteins (Bax, Bak) (56), indicating that the significant reduction in Bcl-2/Bax ratio observed in VSMCs treated with HRM supports the involvement of hydrogen in the apoptotic pathway.

The use of FBS to induce VSMC growth in vitro could be questioned. However, a previous study also using rat VSMCs showed that $10 \%$ FBS was as effective as $20 \mathrm{ng} / \mathrm{ml}$ 
of plateled-derived growth factor (PDGF) to promote VSMC proliferation (51). Furthermore, lercanidipine had the same efficacy in FBS- and PDGF-induced VSMCs, and inhibited Ras-ERK1/2 signaling in the same way, suggesting that FBS and PDGF promote VSMC proliferation using the same pathways.

Significant evidence shows that enhanced VSMC proliferation is a fundamental feature of atherosclerosis pathogenesis. In conclusion, data presented in this report demonstrate that treatment with HRM can effectively inhibit VSMC proliferation and migration in vitro and protect neointimal formation in vivo following vascular injury by balloon angioplasty. These results demonstrate that HRM suppresses the proliferation of VSMCs by inhibiting the ROS, Ras-MEK1/2-ERK1/2 and P13K/Akt pathways. Thus, hydrogen treatment promotes cell cycle arrest in VSMCs at the G0/G1-phase and increases apoptosis rates. HRSS is therefore a potentially useful antioxidant that may prove clinically useful in patients undergoing coronary artery angioplasty, stenting or coronary artery bypass to prevent restenosis.

\section{References}

1. Landau C, Lange RA and Hillis LD: Percutaneous transluminal coronary angioplasty. N Engl J Med 330: 981-993, 1994.

2. van Domburg RT, Foley DP, Breeman A, van Herwerden LA and Serruys PW: Coronary artery bypass graft surgery and percutaneous transluminal coronary angioplasty. Twenty-year clinical outcome. Eur Heart J 23: 543-549, 2002.

3. Sturek M and Reddy HK: New tools for prevention of restenosis could decrease the 'oculo-stento' reflex. Cardiovasc Res 53: 292-293, 2002.

4. Sasaki T, Maruyama H, Kase Y, Takeda S and Aburada M: Antianginal effects of lercanidipine on the vasopressin or methacholine induced anginal model in rats. Biol Pharm Bull 28 811-816, 2005.

5. Park J, Ha H, Seo J, et al: Mycophenolic acid inhibits plateletderived growth factor-induced reactive oxygen species and mitogen-activated protein kinase activation in rat vascular smooth muscle cells. Am J Transplant 4: 1982-1990, 2004.

6. Ohsawa I, Ishikawa M, Takahashi K, et al: Hydrogen acts as a therapeutic antioxidant by selectively reducing cytotoxic oxygen radicals. Nat Med 13: 688-694, 2007.

7. Hong Y, Chen S and Zhang JM: Hydrogen as a selective antioxidant: a review of clinical and experimental studies. J Int Med Res 38: 1893-1903, 2010.

8. Wang C, Li J, Liu Q, et al: Hydrogen-rich saline reduces oxidative stress and inflammation by inhibit of JNK and NF-kappaB activation in a rat model of amyloid-beta-induced Alzheimer's disease. Neurosci Lett 491: 127-132, 2011.

9. Sun H, Chen L, Zhou W, et al: The protective role of hydrogenrich saline in experimental liver injury in mice. J Hepatol 54: 471-480, 2011

10. Sun Q, Kang Z, Cai J, et al: Hydrogen-rich saline protects myocardium against ischemia/reperfusion injury in rats. Exp Biol Med 234: 1212-1219, 2009.

11. Kajiya M, Silva MJ, Sato K, Ouhara K and Kawai T: Hydrogen mediates suppression of colon inflammation induced by dextran sodium sulfate. Biochem Biophys Res Commun 386: 11-15, 2009.

12. Nakao A, Kaczorowski DJ, Wang Y, et al: Amelioration of rat cardiac cold ischemia/reperfusion injury with inhaled hydrogen or carbon monoxide, or both. J Heart Lung Transplant 29: 544-553, 2010

13. Hayashida K, Sano M, Ohsawa I, et al: Inhalation of hydrogen gas reduces infarct size in the rat model of myocardial ischemiareperfusion injury. Biochem Biophys Res Commun 373: 30-35, 2008.

14. Qin ZX, Yu P, Qian DH, et al: Hydrogen-rich saline prevents neointima formation after carotid balloon injury by suppressing ROS and the TNF-alpha/NF-kappaB pathway. Atherosclerosis 220: 343-350, 2012.

15. Wang F, Yu G, Liu SY, et al: Hydrogen-rich saline protects against renal ischemia/reperfusion injury in rats. J Surg Res 167: e339-e344, 2011
16. Shingu $\mathrm{C}$, Koga $\mathrm{H}$, Hagiwara $\mathrm{S}$, et al: Hydrogen-rich saline solution attenuates renal ischemia-reperfusion injury. J Anesth 24: 569-574, 2010.

17. Sun Q, Cai J, Zhou J, et al: Hydrogen-rich saline reduces delayed neurologic sequelae in experimental carbon monoxide toxicity. Crit Care Med 39: 765-769, 2011.

18. Ohsawa I, Nishimaki K, Yamagata K, Ishikawa M and Ohta S: Consumption of hydrogen water prevents atherosclerosis in apolipoprotein E knockout mice. Biochem Biophys Res Commun 377: 1195-1198, 2008.

19. Itoh T, Fujita Y, Ito M, et al: Molecular hydrogen suppresses FcepsilonR I-mediated signal transduction and prevents degranulation of mast cells. Biochem Biophys Res Commun 389: 651-656, 2009.

20. Zheng X, Mao Y, Cai J, et al: Hydrogen-rich saline protects against intestinal ischemia/reperfusion injury in rats. Free Radic Res 43: 478-484, 2009.

21. Clowes AW, Reidy MA and Clowes MM: Kinetics of cellular proliferation after arterial injury. I. Smooth muscle growth in the absence of endothelium. Lab Invest 49: 327-333, 1983.

22. Wei GL, Krasinski K, Kearney M, Isner JM, Walsh K and Andres V: Temporally and spatially coordinated expression of cell cycle regulatory factors after angioplasty. Circ Res 80: 418-426, 1997.

23. Yeh JL, Liou SF, Chang YP, et al: Isoeugenodilol inhibits smooth muscle cell proliferation and neointimal thickening after balloon injury via inactivation of ERK1/2 pathway. J Biomed Sci 15: 375-389, 2008

24. Liou SF, Yeh JL, Liang JC, Chiu CC, Lin YT and Chen IJ: Inhibition of mitogen-mediated proliferation of rat vascular smooth muscle cells by labedipinedilol-A through PKC and ERK 1/2 pathway. J Cardiovasc Pharmacol 44: 539-551, 2004.

25. Parenti A, Bellik L, Brogelli L, Filippi S and Ledda F: Endogenous VEGF-A is responsible for mitogenic effects of MCP-1 on vascular smooth muscle cells. Am J Physiol Heart Circ Physiol 286: H1978-H1984, 2004.

26. Berridge MV, Herst PM and Tan AS: Tetrazolium dyes as tools in cell biology: new insights into their cellular reduction. Biotechnol Annu Rev 11: 127-152, 2005.

27. Muir D, Varon S and Manthorpe M: An enzyme-linked immunosorbent assay for bromodeoxyuridine incorporation using fixed microcultures. Anal Biochem 185: 377-382, 1990.

28. Li JJ, Han M, Wen JK and Li AY: Osteopontin stimulates vascular smooth muscle cell migration by inducing FAK phosphorylation and ILK dephosphorylation. Biochem Biophys Res Commun 356: 13-19, 2007.

29. Fishbein MC, Wang T, Matijasevic M, Hong L and Apple FS: Myocardial tissue troponins T and I. An immunohistochemical study in experimental models of myocardial ischemia. Cardiovasc Pathol 12: 65-71, 2003.

30. Salvemini D, Riley DP and Cuzzocrea S: SOD mimetics are coming of age. Nat Rev Drug Discov 1: 367-374, 2002.

31. Schwartz RS and Henry TD: Pathophysiology of coronary artery restenosis. Rev Cardiovasc Med 3 (Suppl 5): S4-S9, 2002.

32. Braun-Dullaeus RC, Mann MJ and Dzau VJ: Cell cycle progression: new therapeutic target for vascular proliferative disease. Circulation 98: 82-89, 1998.

33. Chen Z, Lee FY, Bhalla KN and $\mathrm{Wu} \mathrm{J}$ : Potent inhibition of platelet-derived growth factor-induced responses in vascular smooth muscle cells by BMS-354825 (dasatinib). Mol Pharmacol 69: 1527-1533, 2006.

34. Stettler C, Wandel S, Allemann S, et al: Outcomes associated with drug-eluting and bare-metal stents: a collaborative network meta-analysis. Lancet 370: 937-948, 2007.

35. Lemos PA, Saia F, Ligthart JM, et al: Coronary restenosis after sirolimus-eluting stent implantation: morphological description and mechanistic analysis from a consecutive series of cases. Circulation 108: 257-260, 2003.

36. Fujii K, Mintz GS, Kobayashi Y, et al: Contribution of stent underexpansion to recurrence after sirolimus-eluting stent implantation for in-stent restenosis. Circulation 109: 1085-1088, 2004.

37. Takebayashi H, Kobayashi Y, Mintz GS, et al: Intravascular ultrasound assessment of lesions with target vessel failure after sirolimus-eluting stent implantation. Am J Cardiol 95: 498-502, 2005.

38. Griendling KK and Ushio-Fukai M: Redox control of vascular smooth muscle proliferation. J Lab Clin Med 132: 9-15, 1998.

39. Kunsch C and Medford RM: Oxidative stress as a regulator of gene expression in the vasculature. Circ Res 85: 753-766, 1999. 
40. Boullier A, Bird DA, Chang MK, et al: Scavenger receptors, oxidized LDL, and atherosclerosis. Ann NY Acad Sci 947: 214-223, 2001.

41. Mizuno Y, Jacob RF and Mason RP: Inflammation and the development of atherosclerosis. J Atheroscler Thromb 18: 351-358, 2011.

42. Szocs K, Lassegue B, Sorescu D, et al: Upregulation of Nox-based $\mathrm{NAD}(\mathrm{P}) \mathrm{H}$ oxidases in restenosis after carotid injury. Arterioscler Thromb Vasc Biol 22: 21-27, 2002.

43. Shi Y, Niculescu R, Wang D, Patel S, Davenpeck KL and Zalewski A: Increased NAD $(\mathrm{P}) \mathrm{H}$ oxidase and reactive oxygen species in coronary arteries after balloon injury. Arterioscler Thromb Vasc Biol 21: 739-745, 2001.

44. Kasai $\mathrm{H}$ : Analysis of a form of oxidative DNA damage, 8-hydroxy-2'-deoxyguanosine, as a marker of cellular oxidative stress during carcinogenesis. Mutat Res 387: 147-163, 1997.

45. Roberts PJ and Der CJ: Targeting the Raf-MEK-ERK mitogenactivated protein kinase cascade for the treatment of cancer. Oncogene 26: 3291-3310, 2007.

46. Lewis TS, Shapiro PS and Ahn NG: Signal transduction through MAP kinase cascades. Adv Cancer Res 74: 49-139, 1998.

47. Lee JH, Johnson PR, Roth M, Hunt NH and Black JL: ERK activation and mitogenesis in human airway smooth muscle cells. Am J Physiol Lung Cell Mol Physiol 280: L1019-L1029, 2001.

48. Koyama H, Olson NE, Dastvan FF and Reidy MA: Cell replication in the arterial wall: activation of signaling pathway following in vivo injury. Circ Res 82: 713-721, 1998.

49. Roovers K, Davey G, Zhu X, Bottazzi ME and Assoian RK: Alpha5beta1 integrin controls cyclin D1 expression by sustaining mitogen-activated protein kinase activity in growth factor-treated cells. Mol Biol Cell 10: 3197-3204, 1999.
50. Hirata A, Igarashi M, Yamaguchi $\mathrm{H}$, et al: Nifedipine suppresses neointimal thickening by its inhibitory effect on vascular smooth muscle cell growth via a MEK-ERK pathway coupling with Pyk2. Br J Pharmacol 131: 1521-1530, 2000.

51. Wu JR, Liou SF, Lin SW, et al: Lercanidipine inhibits vascular smooth muscle cell proliferation and neointimal formation via reducing intracellular reactive oxygen species and inactivating Ras-ERK1/2 signaling. Pharmacol Res 59: 48-56, 2009.

52. Lawlor MA and Alessi DR: PKB/Akt: a key mediator of cell proliferation, survival and insulin responses? J Cell Sci 114: 2903-2910, 2001.

53. Ranganna K, Yatsu FM, Hayes BE, Milton SG and Jayakumar A: Butyrate inhibits proliferation-induced proliferating cell nuclear antigen expression (PCNA) in rat vascular smooth muscle cells. Mol Cell Biochem 205: 149-161, 2000.

54. Wu CH, Lin CS, Hung JS, et al: Inhibition of neointimal formation in porcine coronary artery by a Ras mutant. J Surg Res 99: 100-106, 2001.

55. Grube E, Gerckens U, Muller R and Bullesfeld L: Drug eluting stents: initial experiences. Z Kardiol 91 (Suppl 3): S44-S48, 2002.

56. Donovan $\mathrm{M}$ and Cotter TG: Control of mitochondrial integrity by Bcl-2 family members and caspase-independent cell death. Biochim Biophys Acta 1644: 133-147, 2004. 